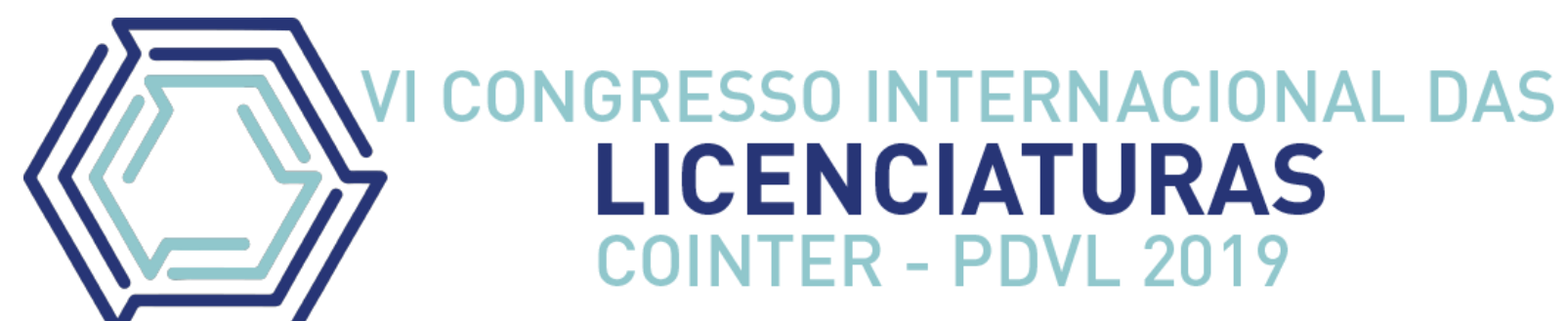

https://cointer.institutoidv.org/pdvl/

\title{
EDUCAÇÃO AMBIENTAL EM UMA ESCOLA DO ENTORNO DA RPPN FAZENDA ALMAS: VIVÊNCIAS INTEGRADORAS COM DISCENTES NO CARIRI PARAIBANO.
}

\author{
EDUCACIÓN AMBIENTAL EN UNA ESCUELA ALREDEDOR DE RPPN \\ FAZENDA ALMAS: EXPERIENCIAS INTEGRATIVAS CON ESTUDIANTES EN \\ CARIRI PARAIBANO.
}

\section{ENVIRONMENTAL EDUCATION IN A SCHOOL AROUND RPPN FAZENDA ALMAS: INTEGRATIVE EXPERIENCES WITH STUDENTES IN CARIRI PARAIBANO.}

\author{
Apresentação: Comunicação Oral
}

Karoline Maria da Silva Soares; Myller Gomes Machado²; Francisco José Pegado Abílio³.

\section{DOI: https://doi.org/10.31692/2358-9728.VICOINTERPDVL.2019.0120}

\begin{abstract}
Resumo
A caatinga ocupa cerca de $10 \%$ de todo território brasileiro e é um dos biomas que mais sofre com a ação antrópica. Diante desse cenário surge a importância de trabalhar com a Educação Ambiental (EA) nessa região não apenas para alertar sobre os impactos ambientais que ocorrem na ocorridos, mas também sensibilizar os cidadãos sobre sua convivência com o meio ambiente. Sendo assim, o objetivo dessa pesquisa foi de desvelar para os discentes das escolas do entorno da RPPN Fazenda Almas a efetivação de uma educação ambiental contextualizada para o bioma Caatinga. A metodologia tratou-se de uma pesquisa de natureza aplicada de abordagem qualitativa, utilizando procedimentos técnicos da pesquisa do participante e elementos da teoria do biorregionalismo. $\mathrm{O}$ trabalho ocorreu com alunos da EEEFM Bartolomeu Maracajá, no município de São José dos Cordeiros-PB. Para análise da percepção dos discentes foram utilizados questionários estruturados pré e pós-teste onde os alunos foram submetidos a questões ambientais. Quando questionados sobre "o que vem a ser meio ambiente" houve categorias que mais se sobressaíram, no pré-teste $42 \%$ dos alunos possuíam uma visão "generalista", já no pós-teste essa porcentagem caiu para $14 \%$ seguido de "como recurso" expressando-se $25 \%$ no pré-teste e $18 \%$ no pós-teste. Quando questionados sobre "o que vem a ser natureza" $35 \%$ dos alunos possuem uma visão "generalista", aparecendo apenas no pré-teste, já no pós-teste a nova categoria que surgiu e que mais sobressaiu foi "como ecossistema". Quando questionados sobre "o que vem a ser EA" 40\%

\footnotetext{
${ }^{1}$ Graduanda em Ciências Biológicas UFPB - CCEN, e-mail : karol_.soares@ hotmail.com

${ }^{2}$ Graduação em Ciências Biológicas UFPB - CCEN Mestrado em Desenvolvimento e Meio Ambiente (PRODEMA-UFPB); Doutorando em Educação - PPGE/UFPB; Professor do Instituto Federal da Paraíba (IFPB). e-mail: myller.machado@ifpb.edu.br

${ }^{3}$ Professor Dr. Titular, Universidade Federal da Paraíba - CE/DME, email: chicopegado@yahoo.com.br
} 
dos discentes responderam no pré-teste que é uma "disciplina curricular", já no pós-teste expressou-se uma nova categoria com $40 \%$ da educação ambiental como sendo "crítica". Quando questionados sobre "quais os impactos ambiental ocorridos na região" $60 \%$ dos discentes no pré-teste associaram as "queimadas" e no pós-teste $45 \%$ associaram aos agrotóxicos, sendo um tema bastante trabalhado nas vivências. Quando questionados sobre a RPPN Fazenda Almas 30\% dos discentes já visitaram o local, 60\% dos discentes nunca visitaram e $20 \%$ nunca ouviram falar. As ações realizadas na escola foi bastante importante para que os discentes pudessem conhecer algumas questões ambientais, bem como conhecer o patrimônio da RPPN Fazenda Almas.

Palavras-Chave: Educação ambienta. Caatinga. Natureza. Meio ambiente.

\section{Resumen}

La caatinga ocupa aproximadamente el $10 \%$ de todo el territorio brasileño y es uno de los biomas que más sufre de acción antrópica. Dado este escenario, surge la importancia de trabajar con Educación Ambiental (EA) en esta región no solo para advertir sobre los impactos ambientales que ocurren en el lugar, sino también para sensibilizar a los ciudadanos sobre su coexistencia con el medio ambiente. Por lo tanto, el objetivo de esta investigación fue revelar a los estudiantes de las escuelas alrededor de RPPN Fazenda Almas la realización de una educación ambiental contextualizada para el bioma Caatinga. La metodología fue una investigación de naturaleza aplicada del enfoque cualitativo, utilizando procedimientos técnicos de la investigación participante y elementos de la teoría del bioregionalismo. El trabajo se realizó con estudiantes de EEEFM Bartolomeu Maracajá, en el municipio de São José dos Cordeiros-PB. Para analizar la percepción de los estudiantes, se utilizaron cuestionarios estructurados previos y posteriores a la prueba, donde los estudiantes fueron sometidos a preguntas ambientales. Cuando se les preguntó sobre "qué es el medio ambiente", hubo categorías que se destacaron, en la prueba previa el $42 \%$ de los estudiantes tenía una visión "generalista", mientras que en la prueba posterior este porcentaje se redujo al 14\% seguido de "como recurso". "Expresando el $25 \%$ en la prueba previa y el $18 \%$ en la prueba posterior. Cuando se les preguntó sobre "qué es la naturaleza", el 35\% de los estudiantes tiene una visión "generalista", que aparece solo en la prueba previa y en la prueba posterior, la nueva categoría que surgió y que se destacó fue "como un ecosistema". Cuando se les preguntó sobre "lo que pasa a ser EA", el 40\% de los estudiantes respondió en la prueba previa que es una "disciplina curricular", mientras que en la prueba posterior se expresó una nueva categoría con el $40 \%$ de la educación ambiental como "crítica". . Cuando se les preguntó sobre "qué impactos ambientales ocurrieron en la región", el 60\% de los estudiantes en la prueba previa asociaron las "quemaduras" y en la prueba posterior el $45 \%$ asociado con los pesticidas, siendo un tema que fue muy trabajado en las experiencias. Cuando se les preguntó acerca de RPPN Fazenda Almas, el 30\% de los estudiantes ya han visitado el sitio, el $60 \%$ de los estudiantes nunca lo han visitado y el $20 \%$ nunca han oído hablar de él. Las acciones llevadas a cabo en la escuela fueron muy importantes para que los estudiantes pudieran conocer algunos problemas ambientales, así como conocer el patrimonio de RPPN Fazenda Almas.

Palabras Clave: Educación Ambiental. Caatinga. Naturaleza. Medio Ambiente. 


\begin{abstract}
Caatinga occupies about $10 \%$ of all Brazilian territory and is one of the biomes that suffer most from anthropic action. Given this scenario emerges the importance of working with Environmental Education (EA) in this region not only to warn about the environmental impacts that occur in the occurred, but also sensitize citizens about their coexistence with the environment. Thus, the purpose of this research was to unveil to the students of the schools around RPPN Fazenda Almas the realization of a contextualized environmental education for the Caatinga biome. The methodology was a research of applied nature of qualitative approach, using technical procedures of the participant research and elements of the theory of bioregionalism. The work took place with students from EEEFM Bartolomeu Maracajá, in São José dos Cordeiros-PB. There were a total of ten pedagogical experiences that took place both in the classroom, with various didactic means, as well as environmental studies at Fazenda Almas. To analyze the students' perception, pre and post-test structured questionnaires were used, where students were submitted to environmental questions. When asked about "what is the environment" there were categories that stood out, in the pretest $42 \%$ of students had a "generalist" view, while in the posttest this percentage dropped to $14 \%$ followed by "as a resource". "Expressing 25\% in the pretest and 18\% in the posttest. When asked about "what comes to be nature" $35 \%$ of students have a "generalist" view, appearing only in the pretest, no longer posttest in a new category that emerged and the most prominent was "as an ecosystem". When asked about "what comes to be environmental education", 40\% of the students answered in the pretest that it is a "curricular discipline", no longer in the posttest was expressed a new category with $40 \%$ of EE as "Critical". When asked about "what are the environmental impacts that occurred in the region" $60 \%$ of students did not associate pre-test as "burned" and not post-test $45 \%$ associated with pesticides, being a subject very worked in the experiences. When asked about RPPN Fazenda Almas, 30\% of the students are already qualified in the place, $60 \%$ of the students never heard and $20 \%$ never heard. As the actions performed at the school were important for those who discuss knowing some environmental issues, as well as knowing the heritage of RPPN Fazenda Almas.
\end{abstract}

Keywords: Environmental education. Caatinga, nature, environment.

\title{
Introdução
}

A Caatinga cobre quase $11 \%$ do território nacional $\left(844.453 \mathrm{Km}^{2}\right)$, e abriga cerca de 25 milhões de pessoas sendo então, considerada uma das regiões mais populosas do mundo. Todavia, $80 \%$ de seus ecossistemas originais já foram alterados, principalmente por desmatamentos e queimadas. Além do mais, $62 \%$ das áreas susceptíveis à desertificação estão em zonas originalmente ocupadas por Caatinga e apenas 1,5\% do bioma está abrangido por Unidades de proteção, assumindo a posição de bioma brasileiro menos protegido (BRASIL, 2018a).

O efeito combinado entre as condições climáticas próprias da região Semiárida paraibana e as práticas inadequadas de uso e aproveitamento do solo e demais recursos naturais além de 
acentuar o desgaste da paisagem natural, levando a perda da biodiversidade e esgotamento de recursos naturais, tem disseminado o processo de desertificação nas áreas susceptíveis, no entanto, buscar a Conservação pela gestão não é algo facilmente executável, principalmente quando as propostas de intervenção apresentadas se contrapõem aos padrões comportamentais da comunidade (GADOTTI, 2000).

Além de enfrentar esses desafios, o Cariri paraibano apresenta ainda um quadro de atraso econômico e social muito grave, assim como uma destruição desenfreada do bioma Caatinga, determinada pela estagnação ou declínio das atividades produtivas tradicionais (ABÍLIO; FLORENTINO; RUFFO, 2010), como também uma perceptível e preocupante falta de políticas públicas para a conservação deste bioma, como a implantação de projetos (e seu desenvolvimento) relacionados à Educação Ambiental (EA), o conjunto de todos os fatores citados leva a destruição desenfreada e assim aumenta o processo de desertificação (ou de áreas susceptíveis) que já se alastra por grande parte da Caatinga, com ênfase maior no estado da Paraíba.

Neste sentido, a escola tem papel fundamental e privilegiado para debater as questões ambientais e assim criar possibilidades para um processo de ensino-aprendizagem relacionado a elementos da política, sociedade, ética, moral, dentro outros, buscando a formação de cidadãos críticos e reflexivos.

Então nada mais adequado que buscarmos o desenvolvimento da cidadania e formação de uma racionalidade ambiental dentro das escolas. Evidenciando assim a importância dos professores no processo de ensino e aprender, sendo a escola o local mais adequado para a realização de um ensino ativo e participativo, buscando o conhecimento e a importância da Biodiversidade do Bioma Caatinga, para manutenção da vida das populações do Cariri paraibano.

Portanto este trabalho teve como desvelar princípios teórico-metodológicos para a efetivação de uma educação ambiental contextualizada para o bioma Caatinga em uma escola do entorno da RPPN Fazenda Almas.

\section{Fundamentação Teórica}

A região Semiárida brasileira abrange aproximadamente 18,2\% da área do país. Já o Nordeste apresenta 86,48\% de seu território na porção Semiárida. O Rio Grande do Norte lidera a lista com 93,4\% do território Semiárido. Depois, vem Pernambuco com 88\%, seguido 
do Ceará e Paraíba com 86\%. Nos demais estados, também há uma predominância do Semiárido: $69,7 \%$ da Bahia, 59,9\% do Piauí, 50,9\% do Sergipe e 45,6\% de Alagoas. Contabilizando uma extensão territorial de $980.133,079 \mathrm{Km}^{2}$ com a presença de 1.135 municípios. Relacionado à população, é aproximadamente $12 \%$ da população brasileira que vive no Semiárido, o que representa 22.598 .318 habitantes, sendo 42,57\% da população nordestina. Equiparando as populações das regiões Norte e Centro-Oeste com a da região Semiárida, observa-se que esta última supera facilmente as dessas regiões e é apenas 17,48\% menor do que a população residente na região Sul. Portanto, percebe-se claramente a grandeza numérica que representa a população residente no Semiárido brasileiro. Vale ressaltar que esta área foi demarcada diversas vezes ao longo dos últimos 75 anos (MEDEIROS et al., 2012; ASA, 2018; CIRILO, et al., 2007).

Já atualmente, do ponto de vista socioeconômico, o Semiárido é o espaço do Brasil onde é manifestado mais intensamente o fosso que separa a base econômica do crescimento demográfico. A economia vai, muitas vezes, de atividades tradicionais de produtividade a industriais e agroindustriais. Para a maioria da população, o tipo de economia é vulnerável ao fenômeno das estiagens (MACAMBIRA, 2006). Qualquer desequilíbrio na distribuição das chuvas, que não possibilite a criação de animais e a produção agrícola, cria caos na economia loco-regional.

A economia atual está interligada com as propriedades dos territórios, uma vez que como afirma Santos, Schistek e Oberhofer (2007), a realidade da situação fundaria, na qual a absoluta maioria das propriedades é constituída de hectares totalmente insuficientes ao necessário para ter uma produção estável é uma consequência direta do modelo da ocupação do Semiárido brasileiro.

Este processo histórico reflete no que temos hoje, a concentração dos territórios para poucas pessoas, como afirma a Articulação no Semiárido (ASA) (2018) o Semiárido é um espaço com grande concentração de terra, da água e dos meios de comunicação, que historicamente sempre estiveram nas mãos de uma pequena elite. Essa situação gera níveis altíssimos de exclusão social e de degradação ambiental e são fatores determinantes da crise socioambiental e econômica vivida na região. Sobre a divisão das terras propícias à agricultura na região, os dados são os seguintes: cerca de 1,5 milhão de famílias agricultoras $(28,82 \%$ de toda a agricultura familiar brasileira) ocupam apenas $4,2 \%$ das terras agricultáveis do Semiárido. Ao passo que 1,3\% dos estabelecimentos rurais com mais de 1 mil hectares, 
conhecidos como latifúndios, detêm $38 \%$ das terras.

Nesta conjuntura, Vilar Filho (2018) elenca alguns fatores que contribuem para as problemáticas da seca: as iniciativas governamentais que só ocorrem durante as estiagens severas, ou seja, sem continuidade; o desenvolvimento de políticas públicas com uma visão hidraulicista, que a água é a solução para todos os problemas; as iniciativas verticais dos governos, como pouca participação efetiva do povo; a não existência de planos assíduos de convivência com a seca; a inatividade das tecnologias disponíveis.

Sobre o bioma dominante, a Caatinga é o que abrange maior área dentro do Semiárido brasileiro, correspondendo a 63\% da área do Semiárido (ABÍLIO; GOMES; SANTANA, 2010), estende-se diferentemente pelos estados de Sergipe, Alagoas, Bahia, Ceará, Paraíba, Pernambuco, Piauí, Rio Grande do Norte, parte do Maranhão e a região norte de Minas Gerais (BERNARDES, 1999). Caracteriza-se por possuir uma vegetação com adaptações ao clima seco e uma paisagem com significativa riqueza biológica, elevado índice de endemismo em espécies animais e vegetais (ABÍLIO; GOMES; SANTANA, 2010), estimando-se que pelo menos $40 \%$ das espécies da flora identificadas sejam endêmicas (LEAL et al, 2005).

Sobre as causas dos impactos ambientais, o crescimento da população e da densidade populacional contribui para a exploração dos recursos naturais além de sua capacidade de suporte. O aumento da população, assim como das demandas por alimentos, energia e outros recursos naturais vêm provocando importantes impactos na base de recursos naturais das regiões da Caatinga (ABÍLIO; FLORENTINO, 2010a).

Pertinente ao estado que foi realizada a pesquisa, a Caatinga é o tipo de vegetação que cobre a maior parte do território Semiárido paraibano e antes de tudo, é preciso superar a ideia de este bioma está relacionado com a pobreza paisagística e de biodiversidade (ARAÚJO; SOBRINHO, 2009).

Mais especificamente, o trabalho foi desenvolvido no Cariri paraibano, este segundo Pereira (2008) localiza-se em áreas tidas como de alta susceptibilidade à ocorrência de processos de desertificação. Além de sofrer degradações naturais, passa por níveis intensos de antropização principalmente no que se refere aos processos de agriculturização e pecuarização.

Segundo Leff (2012), apesar dos avanços verificados, tanto na busca de um modelo de Desenvolvimento Sustentável (DS), como na construção de um Saber Ambiental que incorpora a pluralidade axiológica e a diversidade cultural na formação do conhecimento e da 
maior consciência geral acerca da necessidade de conservação do meio ambiente, constata-se que o humano continua a subestimar os impactos decorrentes de sua ocupação sobre o planeta, não sendo diferente no Cariri paraibano.

Portanto é extremamente significativo o desenvolvimento de práticas de EA na Caatinga, principalmente em regiões onde o processo de devastação da biodiversidade já está acentuado, necessitando assim uma mudança de postura das sociedades que neste espaço vivem, buscando assim estabelecer novas relações, entendendo que o humano não apenas transforma o ambiente na qual insere-se, mas que ele também é o ambiente.

\section{Metodologia}

Para tanto, tratou-se de uma pesquisa de natureza aplicada (PRODANOV; FREITAS, 2013), de abordagem qualitativa e de procedimentos técnicos da pesquisa participante, onde se utilizou dos pressupostos teórico-metodológicos e elementos da Teoria do Biorregionalismo.

A pesquisa é aplicada, pois busca gerar conhecimentos para solução de problemas que contenham objetivos anteriormente definidos (PRODANOV; FREITAS, 2013). É Qualitativa por permitir explorar dados relativos à vivência dos alunos e compreende-los inserido no próprio contexto, sem, no entanto, privilegiar aspectos numéricos, embora possa fazer uso destes, mas a capacidade de reflexão da realidade de forma contextualizada (GIL, 2016). É pesquisa participante por ser desenvolvida a partir da interação do pesquisador com os alunos (participantes das oficinas pedagógicas) em situações participativas e de investigação (PRODANOV; FREITAS, 2013). Possui elementos da teoria do Biorregionalismo assim, estabelecendo espaços de discussão e análise, como estratégia para compreensão das temáticas em relação à EA.

O projeto intitulado "Consolidação e conservação da RPPN Fazenda Almas/PB mediante ao seu Plano de Manejo" foi realizado na Escola Estadual de Ensino Fundamental e Médio Bartolomeu Maracajá - São José dos Cordeiros/PB, com alunos do $7^{\circ}$ ano e da $1^{\circ}$ série, respectivamente, do ensino Fundamental e Médio, no período de abril a dezembro de 2018, com intervalos mensais, sendo trabalhada as mais diversas temáticas em Educação Ambiental, com o intuito de sensibilizar os discentes sobre a importância das unidades de conservação e sua relação com a preservação dos recursos naturais e promoção da qualidade de vida da sociedade. 
A RPPN Fazenda Almas é a quarta maior RPPN do bioma Caatinga e a maior do estado da Paraíba. Localiza-se entre o município de São José dos Cordeiros e o município de Sumé (LIMA, 2004) (Figura 01).

A RPPN foi criada em 1990 e tem uma superfície de 3.505 hectares de um total de 5.247 hectares da Fazenda. Esta tem microclima e está numa altitude entre 600 à 780 m, depositária de remanescentes florestais das diversas tipologias florísticas do domínio da caatinga, incluindo diversas espécies ameaçadas de extinção, sítios arqueológicos, rica em patrimônio histórico (ciclo do algodão) e ainda vibrante no seu folclore. A RPPN encontra-se inserida na microrregião do Cariri paraibano, na porção limite entre as Ecorregiões Planalto da Borborema e Depressão Sertaneja Setentrional (VELOSO et al, 2002).

Figura 01 - Localização dos municípios de São José dos Cordeiros e Sumé, onde encontra-se inserida a RPPN Fazenda Almas.

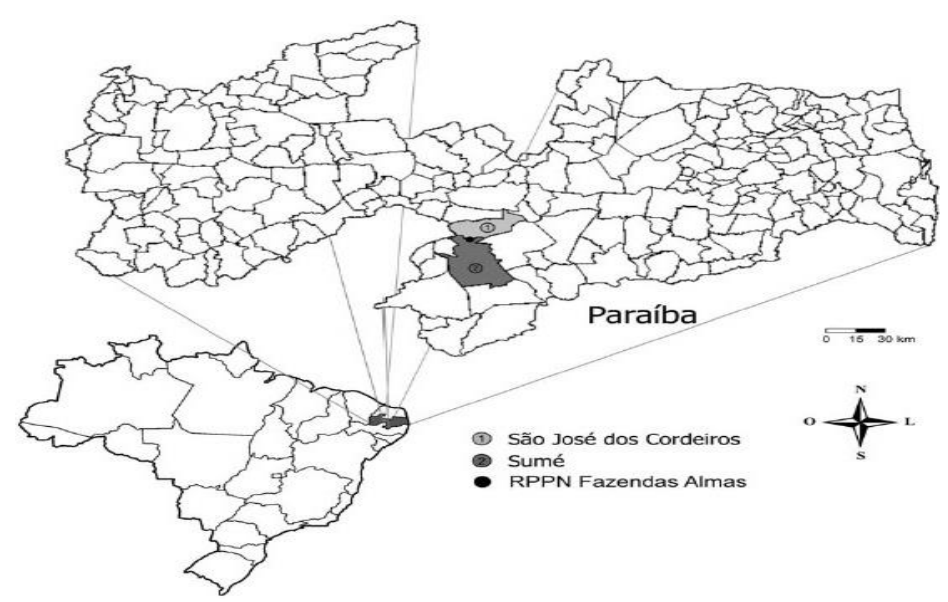

Fonte: Retirado de ARAÚJO, V. F. P. ${ }^{4}$

Para diagnóstico da percepção dos discentes, foram utilizados questionários estruturados pré e pós-teste, o uso de questionários pré-teste tem uma suma importância, pois a partir dele podemos encontrar as dificuldades que os discentes apresentam sobre as questões que serão levantadas no decorrer do projeto, assim é possível escolher as melhores estratégias metodológicas, aumentando a eficiência das vivências. Para Richardson (1999) o uso de questionários prévios ajudam a identificar particularidades que irão influir durante a pesquisa.

\footnotetext{
${ }^{4}$ Fonte: ARAÚJO, V. F. P. Arthopoda de Solo em um Ecossistema Semiárido da Região Neotropical: Composição, variabilidade temporal e estratificação. Dissertação (Mestrado) - Universidade Federal do Rio Grande do Norte. Programa de Pós-graduação em Ciências Biológicas, Natal-RN, 2008.
} 
Dentre as modalidades didáticas, o projeto deu-se principalmente através de exposição dialogada, oficinas pedagógicas (RIBEIRO; FERREIRA, 2001), estudo do meio (ZÓBOLI, 2004) e exposição científica (MANCUSO, 2000; LIMA, 2008).

\section{Resultados e Discussão}

Após a análise dos questionários pré e pós-teste dos discentes do $7^{\circ}$ ano da EEEFM Bartolomeu Maracajá, acerca do perfil socioeconômico dos discentes podemos observar pertinente à orientação de sua expressão de gênero, que 52\% dos discentes afirmam ser do sexo feminino e $48 \%$ do sexo masculino. Em relação à ocupação fora da escola, $4 \%$ afirma ser auxiliar de construção, 24\% afirmam praticar algum esporte (futebol ou futsal), 40\% música, $28 \%$ ajudam em casa e $4 \%$ não responderam (Gráfico 1).

Gráfico 1: Ocupação dos discentes do $7^{\circ}$ ano fora da escola da EEEFM Bartolomeu Maracajá.

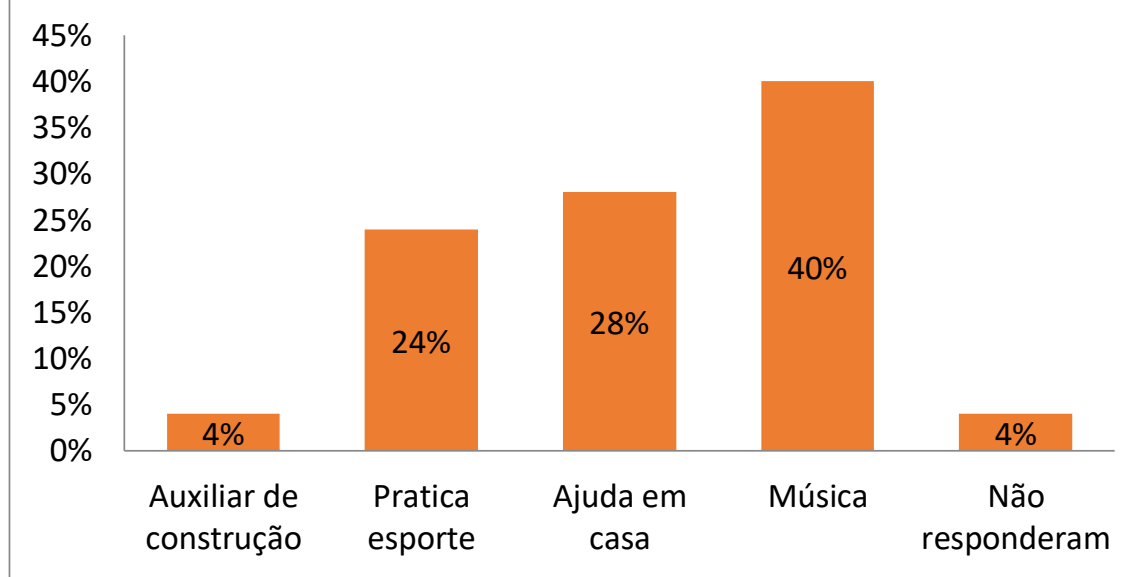

Fonte: Própria (2019).

Uma ocupação bastante citada pelos discentes foi a de "música" (40\%), fato deve-se, pois a cidade possui uma orquestra sinfônica que faz shows durante todo o ano e incentiva os alunos a participarem e tocaram algum instrumento. A presença de música no dia a dia dos discentes pode trazer bastante estímulo, segundo Góes (2009), a principal finalidade da música objetivo da música no espaço escolar é contribui pra o desenvolvimento do aluno por proporcionar a ela ampliação cultural, enriquecimento de sua inteligência e evolução da sensibilidade musical. De acordo com Bastian (2009) os discentes que tem a oportunidade de ter experiências musicais são capazes de alçarem maiores níveis de sensibilização e sociabilidade, tornando-se menos agressivos em sala de aula, assim traz diversos benefícios no processo de ensino e aprendizagem.

Quando questionados sobre "No seu ponto de vista, o que vem a ser meio ambiente" os discentes apresentaram as seguintes percepções como mostra no Gráfico 2. 
Gráfico 2: Percepção dos discentes do $7^{\circ}$ ano da EEEFM Bartolomeu Maracajá acerca do que vem a ser meio ambiente

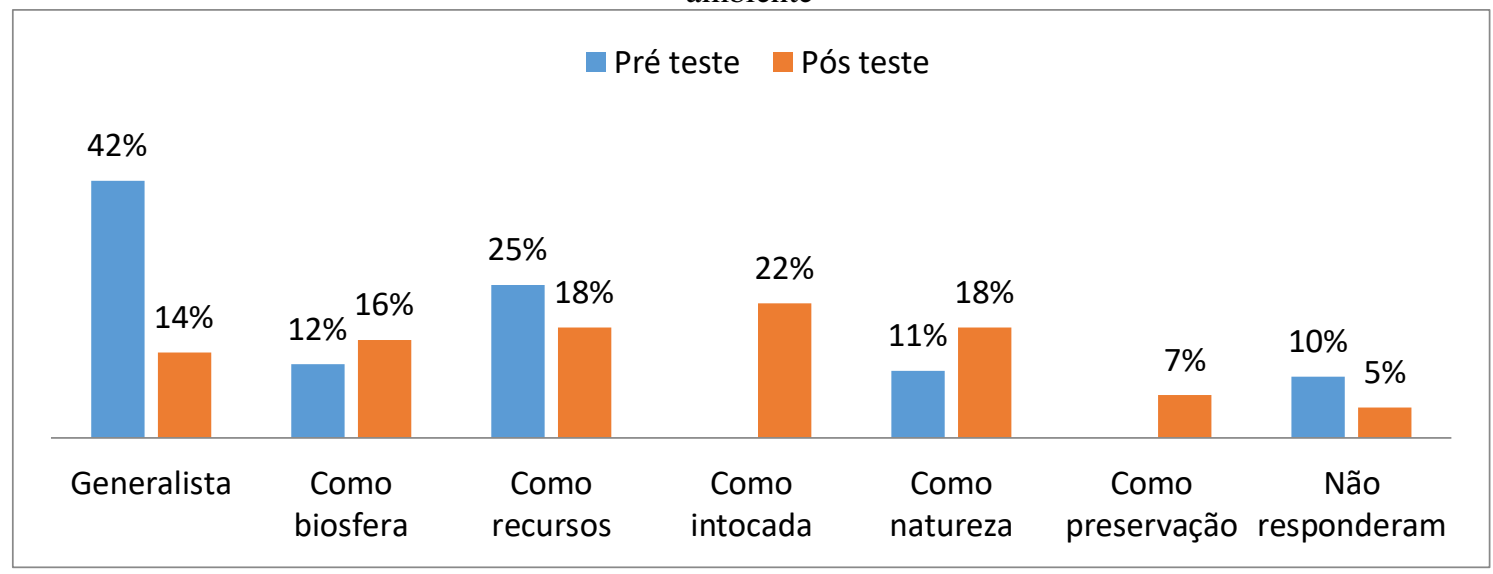

Fonte: Própria (2019).

Em relação à categoria "generalista" podemos observar que houve uma mudança significativa na percepção dos discentes, cerca de $42 \%$ no pré-teste e $14 \%$ no pós-teste, esta categoria pode ser caracterizada como uma visão confusa dos alunos diante à temática. Seguida de "como recurso", esta categoria os discentes enxergam o meio ambiente como fonte de matéria prima, onde representou $25 \%$ no pré-teste e $18 \%$ no pós-teste. A categoria "como biosfera" expressou-se com $12 \%$ no pré-teste e $16 \%$ no pós-teste e pode ser descrita quando o aluno se refere ao meio ambiente como sendo o todo, a terra, onde a cidadania vive (SATO, 2002). A categoria "como natureza" é expressa com $11 \%$ no pré-teste e $18 \%$ no pósteste, "não responderam" $15 \%$ no pré-teste e $5 \%$ no pós-teste. As categorias "como intocada" e "como preservação" apareceram apenas no pós-teste com $22 \%$ e $7 \%$ respectivamente, as respostas categorizadas aparecem no Quadro 1.

Quadro 1: Respostas dos discentes do $7^{\circ}$ ano da EEEFM Bartolomeu Maracajá acerca do que vem a ser Meio ambiente.

\begin{tabular}{|c|l|}
\hline Categoria & \multicolumn{1}{|c|}{ Respostas } \\
\hline \multirow{2}{*}{ Generalista } & Pré-teste: "É tudo que está ao nosso redor." Aluno $7^{\circ}$ ano. \\
\cline { 2 - 2 } & Pós-teste: "É aquilo que conseguimos ver." Aluno $7^{\circ}$ ano. \\
\hline \multirow{2}{*}{ Como biosfera } & Pré-teste: É o no nosso planeta. Aluna $7^{\circ}$ ano. \\
\cline { 2 - 2 } & Pós-teste: "Tudo que existe na terra". Aluno $7^{\circ}$ ano. \\
\hline \multirow{2}{*}{ Como recurso } & Pré-teste: "Tudo que utilizamos". Aluna $7^{\circ}$ ano. \\
\cline { 2 - 2 } & Pós-teste: "Aonde se encontram todos os recursos". Aluno $7^{\circ}$ ano. \\
\hline Como intocada & Pós-teste: "É parte da natureza intocada pelo homem". Aluna $7^{\circ}$ ano. \\
\hline Como natureza & Pré-teste: "Faz parte da natureza". Aluno $7^{\circ}$ ano. \\
\cline { 2 - 2 } & Pós-teste: "É aquilo que é natural". Aluno $7^{\circ}$ ano. \\
\hline Como preservação & Pós-teste: "É a parte preservada do ambiente." Aluna $7^{\circ}$ ano. \\
\hline
\end{tabular}

Fonte: Própria (2019)

Foi perguntado aos discentes nos questionários pré e pós-testes "No seu ponto de vista, o que vem a ser natureza"? Podemos perceber as mudanças nas respostas dos alunos antes e 
após as vivências pedagógicas, como mostra o Quadro 2.

Quadro 2: Respostas dos discentes do $7^{\circ}$ ano da EEEFM Bartolomeu Maracajá acerca do que vem a ser natureza.

\begin{tabular}{|c|c|}
\hline Categoria & Respostas \\
\hline Generalista & Pré-teste: "É aquilo que conseguimos ver." Aluno $7^{\circ}$ ano. \\
\hline Ecossistema & $\begin{array}{l}\text { Pós-teste: "Natureza é um conjunto de ecossistemas aonde vivem as plantas } \\
\text { e os animais" Aluno, } 7^{\circ} \text { ano. }\end{array}$ \\
\hline \multirow[t]{2}{*}{ Recurso } & Pré-teste: "De onde tiramos nossa água e alimentos. Aluna, $7^{\circ}$ ano." \\
\hline & $\begin{array}{l}\text { Pós-teste: "Natureza são todos os recursos que o ser humano não tocou" } \\
\text { Aluno, } 7^{\circ} \text { ano. }\end{array}$ \\
\hline \multirow[b]{2}{*}{ Lugar } & Pré-teste: "Lugar aonde tem árvores, rios e etc". Aluna, $7^{\circ}$ ano. \\
\hline & $\begin{array}{l}\text { Pós-teste: "Natureza é o lugar aonde os animais vivem em harmonia sem } \\
\text { interferência do homem." Aluna, } 7^{\circ} \text { ano. }\end{array}$ \\
\hline
\end{tabular}

Fonte: Própria (2019).

Para os discentes no pré teste, a maioria das respostas, cerca de $35 \%$ se enquadram na categoria "generalista", este fato pode ter ocorrido pois os discentes não sabiam diferenciar conceitos de meio ambiente e natureza, visto que durante as vivências tais conceitos eram bastante confundidos. Em seguida temos a categoria "como lugar", cerca de $25 \%$ no pré teste e 35\% no pós teste, geralmente aqui estão categorizadas resposta dos discentes falam que é a natureza é onde está fauna e flora, retirando totalmente o ser humano deste contexto. A categoria "como recurso" aparece com $25 \%$ no pré-teste e $15 \%$ no pós-teste, essa categoria possui uma visão mais exploratória da natureza, este fato deve ocorrer, pois o cariri paraibano é um local amplamente devastado por ações antrópicas. A categoria "não responderam" obteve $15 \%$ no pré-teste e $10 \%$ no pós-teste. Por fim a categoria "como ecossistema" (45\%) apareceu apenas no pós-teste e com a maioria das respostas como pode ser visto na Gráfico 3.

Para Sato (2002) a educação ambiental pode auxiliar a sociedade a diagnosticar as causas, os efeitos e assim a complexidade dos problemas ambiental, em consequência disso a necessidade de resolvê-los.

Gráfico 3: Percepção dos discentes do $7^{\circ}$ ano da EEEFM Bartolomeu Maracajá acerca do que vem a ser natureza.

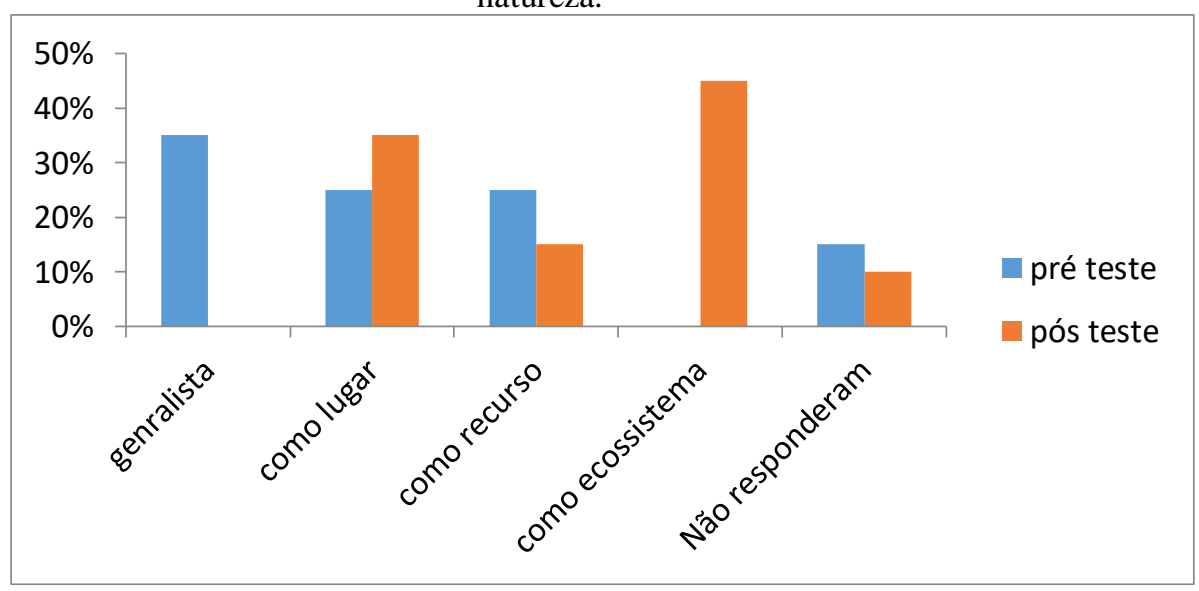


Fonte: Própria (2019)

Quando questionados sobre "o que vem a ser educação ambiental", 40\% dos discentes responderam no pré-teste que era "disciplina curricular" e $8 \%$ pós-teste, nesta categoria geralmente os alunos confundem essa tipologia como uma disciplina que deve ser ensinada nas escolas e ao decorrer das vivências essa visão vai sendo desconstruída, podemos observar que nesta pesquisa que a porcentagem desta categoria diminuiu drasticamente. $\mathrm{Na}$ categoria "conservacionista" corresponderam a 20\% no pré-teste e $10 \%$ no pós-teste, nesta busca a valorização e a conservação dos recursos naturais. Na categoria "preservacionista" valoriza a preservação dos recursos naturais e nesta pesquisa $10 \%$ dos alunos se enquadraram na mesma no pré-teste e $20 \%$ no pós-teste.

Vale ressaltar que existem diferenças entre preservação e conservação, na conservação o ser humano pode utilizar-se dos recursos naturais de maneira sustentável e preocupando-se com o futuro, já a preservação o ser humano não pode fazer uso dos recursos naturais tornando-os intocáveis, esses conceitos foram amplamente debatido com os discentes. $\mathrm{Na}$ categoria "sensibilizadora" enquadram-se $10 \%$ dos alunos no pré-teste e $14 \%$ no pós-teste, nesta não houve diferença significativa na respostas dos discentes, esta categoria busca sensibilizar os alunos quanto às questões ambientais e a melhor utilização dos recursos naturais. A categoria "generalista" apareceu 20\% dos discentes no pré-teste e $8 \%$ no pós-teste, esta categoria representa os alunos que tiveram uma resposta confusa sobre o tema. Por ultimo a categoria "crítica" teve o resulto mais representativo nesta pesquisa, no pré-teste os discentes não categorizaram a educação ambiental como sendo crítica e ao serem questionados responderam que nunca tinham ouvido falar e após as vivências somaram $40 \%$ dos discentes, assim a educação ambiental crítica mostra-se totalmente diferente da conservadora e busca problematizar, politizar e levar para os alunos a importância das questões ambientais para a realidade dos mesmos (Gráfico 4). 
Gráfico 4: Percepção dos discentes do $7^{\circ}$ ano da EEEFM Bartolomeu Maracajá acerca do que vem a ser educação ambiental.

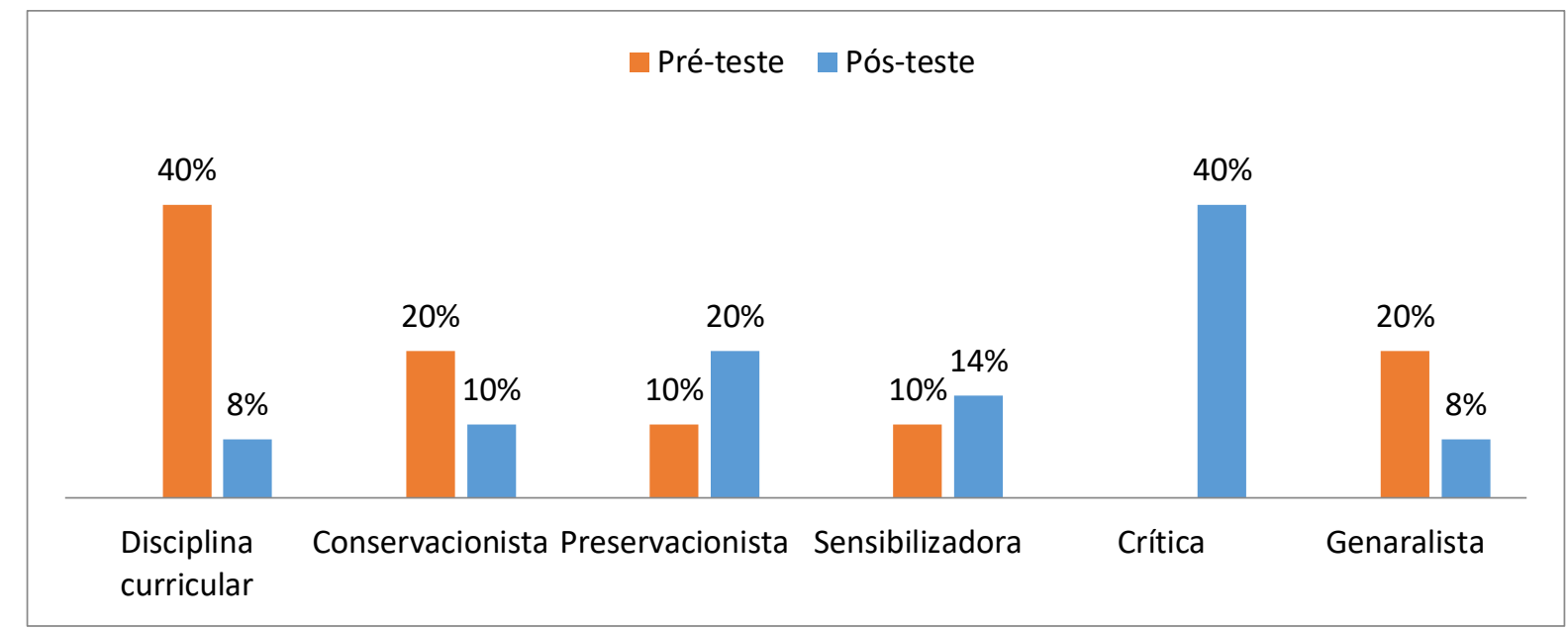

Fonte: Própria (2019).

Acerca dos impactos ambientais que ocorrem na região foi questionado aos discentes "quais os impactos ambientais ocorridos na região", no pré-teste cerca de $40 \%$ não responderam, durante sãs vivências foi possível observar que os alunos até tinha idéia dos impactos ocorridos, mas não conseguiram fazer associação com o termo "impacto ambiental". Ainda no pré-teste $60 \%$ mencionaram "queimadas" e $40 \%$ no pós-teste, $35 \%$ citaram "caça" no pré-teste e $20 \%$ no pós-teste e $50 \%$ mencionaram "lixo" no pré-teste $25 \%$. Houveram categorias que só foram expressas no pós-teste como agrotóxicos com $45 \%$, agricultura $20 \%$, pecuária 30\% e desertificação 40\% como podemos observar no Gráfico 5.

Podemos observar que a categoria "desertificação "apareceu apenas no pós-teste e foi a que mais se sobressaiu, a desertificação é causada principalmente pelas queimadas e desmatamentos que ocorrem na região, principalmente pela prática da pecuária e agricultura desenfreada. Segundo Brasil (2016) para ser considerado um impacto ambiental é necessário que haja mudanças físicas, químicas e biológicas causadas pelo ser humano a qualquer forma de matéria e afetem a qualidade dos recursos ambientais, sendo assim, todas as categorias citadas pelos discentes correspondem a um impacto ambiental. 
Gráfico 5: Percepção dos discentes do $7^{\circ}$ ano da EEEFM Bartolomeu Maracajá acerca dos impactos ambientais ocorridos na região.

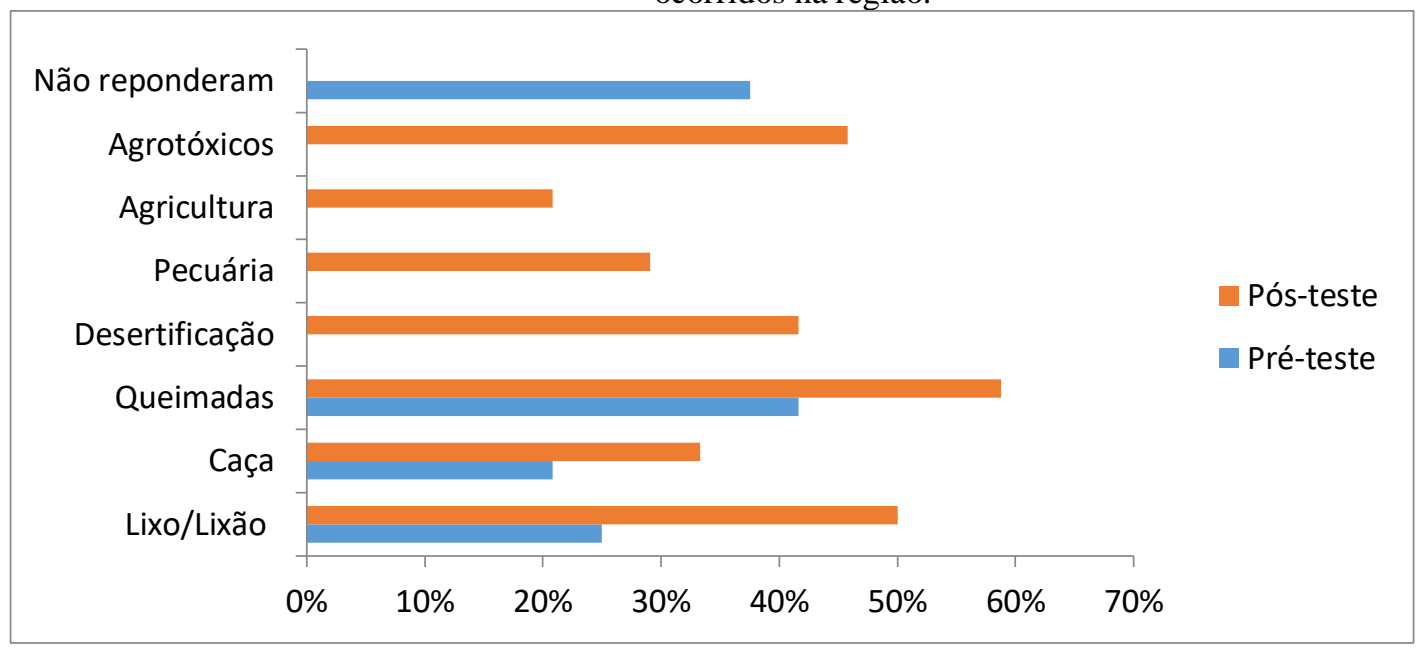

Fonte: Própria (2019)

Quando questionados sobre a RPPN Fazenda Almas 30\% dos discentes já visitaram o local, $60 \%$ dos discentes nunca visitaram e $20 \%$ nunca ouviram falar. Algumas ações em educação ambiental já foram desenvolvidas na escola com professorem e outras turmas.

\section{Atividades Desenvolvidas}

A primeira vivência educativa foi realizada no dia 28 de Abril de 2018 e teve como tema "Educação Ambiental com ênfase na RPPN Fazenda Almas: a importância da conservação da biodiversidade". A importância de iniciar as atividades educativas com uma reflexão acerca da Educação Ambiental decorreu da necessidade de construir um processo de reconhecimento de valores e clarificações de conceitos e, assim, compreender as interrelações existentes entre o ser humano, suas culturas e seus meios biofísicos (UNESCO, 1977). Após a explicação do projeto os alunos foram submetidos a um questionário pré-teste sobre as possíveis temáticas que seriam tratadas durante o projeto, com a finalidade de identificar as possíveis dificuldades dos conteúdos apresentados.

A segunda vivência educativa foi realizada no dia 11 de Maio de 2018 e teve como temática principal "Conhecendo os Moluscos: caracterização geral do filo. Espécies que ocorrem no Cariri paraibano bem como na Fazenda Almas". Esta vivência foi totalmente voltada à parte prática, onde os alunos eram construtores do próprio conhecimento. A atividade sobre os moluscos foi escolhida por conta da necessidade de levar conhecimento sobre os espécimes ocorridos e não ocorridas na região do cariri paraibano, onde eles tiveram a oportunidade de visualizar animais a olho nu e na lupa as principais espécies. 
A terceira vivência educativa ocorreu no dia 22 de Junho e teve como tema "Caracterização geral do Semiárido brasileiro, do bioma Caatinga e da RPPN Fazenda Almas", nesta vivência os alunos puderam aprender conceitos e curiosidades sobre o bioma caatinga e também como um primeiro contato com a Fazenda Almas, visto que a maioria nunca tinha ouvido falar. Após a exposição da aula dialogada, os alunos fizeram a atividade "Dinâmica dos conceitos" no qual eles tinham que completar as frases com os principais conceitos expostos na aula. Ao final da explanação os alunos foram divididos em duplas para completarem seus conceitos, em seguida compartilharam com os demais colegas de classe, gerando assim um debate bastante produtivo.

A quarta vivência educativa sucedeu-se no dia 27 de Julho e foi tratada a temática "Fauna e Flora da Caatinga bem como da RPPN Fazenda Almas". Nesta vivência os discentes puderam explorar seus conhecimentos prévios sobre a fauna e flora da região, bem como sua riqueza e importância econômica e para manutenção do equilíbrio ambiental. Além da exposição do conteúdo dialogado, também houve a parte prática, onde os discentes foram divididos em pequenos grupos para aplicação de diversas atividades a primeira deu-se através do jogo caça-palavras, sobre as plantas que ocorriam na região.

A segunda atividade tinha como tema animais endêmicos exóticos, onde eles tinham que recortar e colar em respectivos lugares os animais que ocorriam e não ocorriam na região da Caatinga. Por fim, a terceira e ultima atividade pratica a sala foi reorganizada em dois grupos para o jogo “o que é o que é?" sobre a fauna e flora da região, onde cada grupo tinha direito a uma resposta, caso errasse ou não soubesse.

A quinta vivência educativa teve como tema "Impactos Ambientais ocorridos na Caatinga" e foi realizada no dia 17 de agosto. Após a exposição dialogada houve num debate sobre tais questões os ambientais. Em seguida foi realizada uma atividade em forma de cruzadinha, no qual continham perguntas sobre a temática trabalhada, dentre elas sobre desertificação, agrotóxicos, queimadas, caça predatória, dentre outras. No final os alunos dividiram-se em grupos, escolheram um impacto ambiental que mais chamou atenção e discutiram em forma de pequenos seminários com os outros colegas. Por fim foi mostrado um vídeo sobre "Impactos ambientais na Caatinga" com a finalidade de sensibilizar os alunos.

A sexta vivência educativa ocorreu no dia 14 de setembro e deu-se através de uma exposição dialogada. Teve como conteúdo "Impactos Ambientais ocorridos no entorno da RPPN Fazenda Almas", tendo como objetivo sensibilizar os alunos acerca dos Impactos 
Ambientais do Cariri paraibano. Após o término da exposição dialogada, houve a execução de uma oficina pedagógica que constituiu na confecção de cartazes, os alunos foram divididos em grupos e foi pedido para que eles desenhassem através da sua interpretação pessoal duas situações, a primeira sobre o que seria caatinga e a outra sobre algum impacto ambiental que ocorria na região. Após a construção dos cartazes houve uma pequena apresentação dos grupos, formando assim um debate bastante interativo sobre as temáticas escolhidas que foram: pecuária; lixão a céu aberto; caça predatória; queimadas; desmatamento e biopirataria. Os cartazes construídos foram expostos na VII Mostram Cultural e Científica que ocorreu no mês de novembro.

A sétima vivência educativa ocorreu no dia 19 de outubro e teve como tema "Desenvolvimento sustentável para convivência com o semiárido", foi trabalhado com a turma do $7^{\circ}$ ano conceitos importante que foram vistos durantes os meses anteriores, bem como a importância do desenvolvimento sustentável, quais as dificuldades encontradas para se obter este desenvolvimento, quais as consequências que isso acarreta para a natureza e quais alternativas que poderíamos tomar para que esse desenvolvimento possa ser realizado, tanto pela população como pelas grandes empresas. Ao final da exposição dialogada os alunos foram divididos em grupo, que teve como objetivo produzirem um texto sobre como eles poderiam conviver com o semiárido, em seguida esse texto foi utilizados em um teatro fantoches interpretado pelos alunos. Ao final houve um debate sobre quais as dificuldades que eles encontravam na cidade para executar um desenvolvimento sustentável.

$\mathrm{Na}$ apresentação do teatro de fantoches era possível notar o entusiasmo dos alunos em poder interpretarem a história que haviam escrito, de acordo com Galvão (1996), "os participantes parecem receber bem melhor e armazenar com mais facilidade as imagens, quando são apresentadas através de algo que as encante emocionalmente como é o caso do Teatro de Bonecos".

A oitava vivência educativa ocorreu no dia 16 de novembro, esta atividade sucedeuse através de um estudo do meio na RPPN Fazenda Almas. Inicialmente foi debatido historicamente como havia sido criada a RPPN, em seguida os alunos seguiram pela trilha da bola, onde houve um debate sobre fauna, flora e os impactos ambientais que ocorriam na região.

A realização de Estudos do Meio é motivadora para os alunos, pois desloca o ambiente de aprendizagem para fora da sala de aula (BRASIL, 2002). Permite a aquisição de atitudes de 
observação crítica da realidade e despertar da sua curiosidade assim como possibilita a percepção integral da realidade local e obtenção de dados informativos sociais, políticos, históricos, geográficos, econômicos, que o ajudarão a analisar melhor a realidade que o rodeia (ZÓBOLI, 2004).

A nona vivência educativa ocorreu a VII Mostra Cultural e Científica da Escola Bartolomeu Maracajá/São José dos Cordeiros - PB, onde o grupo GEPEBio/UFPB levou matérias de pesquisa e intervenção que realizam em projetos simultâneos sobre a biodiversidade de moluscos, bem como as atividades apresentadas ao longo dos relatórios mensais deste presente projeto.

A realização da Mostra Cultural nas escolas traz uma série de benefício para alunos, professores e comunidade, pois traz novas idéias que podem ser aplicadas no dia a dia. Mancuso (2000) destaca as seguintes mudanças: O crescimento pessoal e a ampliação dos conhecimentos, pois alunos e professores mobilizam-se para buscar e aprofundar temas científicos que, geralmente, não são debatidos em sala de aula; a ampliação da capacidade comunicativa devido à troca de ideias, ao intercâmbio cultural e ao relacionamento com outras pessoas; o desenvolvimento da criticidade com o amadurecimento da capacidade de avaliar o próprio trabalho e o dos outros; maior politização dos participantes devido ampliação da visão de mundo, à formação de lideranças e à tomada de decisões durante a realização dos trabalhos.

A décima vivência educativa ocorreu no dia 08 de dezembro, sucedeu-se através de um estudo do meio na RPPN Fazenda Almas, com os alunos do $1^{\circ}$ ano da Escola Bartolomeu Maracajá. Nesta atividade os alunos puderam conhecer os espaços comuns da fazenda e realizaram a trilha da Pedra da Bola, onde puderam ver diversas espécies de vegetais através das placas de identificação contidas na trilha.

\section{Conclusões}

Após análise dos questionários pré e pós-teste pôde-se notar uma diferença significativa na visão dos discentes em relação ao conceito de natureza, onde no pré-teste sobressaiu-se a visão "generalista" onde no pós-teste não se manifestou, aparecendo uma nova categoria denominada "como ecossistema". Sobre conceito de meio ambiente houve uma queda significativa da categoria "generalista" no pós-teste dando assim espaço para outras categorias como "preservação" e "intocada". Quando ao conceito de EA no pré-teste 
sobressaiu-se também a categoria "generalista" e no pós-teste a de EA como sendo "crítica. As mudanças nas percepções dos discentes deu-se por meio vivências pedagógicas realizadas, onde participavam ativamente e trouxe algo significativo para a sua realidade fora da escola. Em relação aos impactos ambientais foi possível notar durante as vivências que eles possuíam um conhecimento prévio sobre a degradação ambiental, visto que faz parte da realidade e do cotidiano dos mesmos. As ações realizadas na escola Bartolomeu Maracajá localizada do entorno da RPPN Fazenda Almas trouxeram uma grande importância para a comunidade escolar, pois a maioria dos alunos apenas tinha ouvido falar da RPPN, mas nunca tido a oportunidade de visitá-la.

Assim através deste trabalho além de conhecer na teoria, através de fotos mostradas nos slides, algumas turmas da escola puderam visitar a fazenda e conhecer os encantos e belezas que existe no local. Infelizmente nem todas as turmas puderam fazer à visita devido à falta de transporte para deslocá-los ao local. Mesmo com esse empecilho pode-se concluir que o trabalho mostrou-se de grande importância para os alunos que tinham uma visão distorcida sobre EA, onde através dos diálogos era notório que houve reflexão sobre todas as temáticas tratadas com possíveis mudanças atitudinais posteriores. Em conversas informas com os alunos fora da sala de aula, era possível perceber o quanto eles estavam entusiasmados com o conteúdo e ansiosos para conhecer os limites da RPPN Fazenda Almas e seu contexto histórico, assim para que essa conscientização pudesse ter um efeito ainda maior, seria interessante a continuidade desta pesquisa nas escolas do entorno, pois é âmbito formal onde se torna possíveis aberturas para tais diálogos.

\section{Referências}

ABÍLIO, F. J. P.; FLORENTINO, H. S. Impactos ambientais na Caatinga. In: ABÍliO, F. J. P. (Org). Bioma Caatinga: Ecologia, biodiversidade, educação ambiental e práticas educativas. João Pessoa: Ed. Universitária, 2010a.

ABÍliO, F. J. P.; FlORENTINO, H. S.; RUFFO, T. L. M. Educação Ambiental no Bioma Caatinga: formação continuada de professores de escolas públicas de São João do Cariri, Paraíba. Pesquisa em Educação Ambiental, vol. 5, n. 1, p. 171-193, 2010.

ABÍlIO, F. J. P.; GOMES, C.S.; SANTANA, A.C.D. Bioma Caatinga: caracterização e aspectos gerais. In: ABÍLIO, F.J.P. (Org.). Bioma Caatinga: ecologia, biodiversidade, educação ambiental e práticas pedagógicas. João Pessoa: UFPB/ Ed. Universitária, 2010, p.13-30.

ARAÚJO, C.S.; SOBRINHO, J.F. O Bioma Caatinga no Entendimento dos Alunos da Rede Pública de Ensino da Cidade de Sobral - Ceará. Revista Homem, Espaço e Tempo, 2009. 
Articulação do Semiárido (ASA). Semiárido - é no Semiárido que a vida pulsa! Disponível em: 〈http://www.asabrasil.org.br/semiarido>. Acesso em: 26 Abr. 2018.

BASTIAN, H. Música na Escola: a contribuição do ensino da música no aprendizado e no convívio social da criança. São Paulo: Paulinas, 2009.

BRASIL. PCN + Ensino Médio: Orientações Educacionais complementares aos Parâmetros Curriculares Nacionais. Ciências da natureza, matemática e suas tecnologias. Brasília: MEC; SEMTEC, 2002.

BRASIL. Política Nacional de Meio Ambiente. Lei $\mathrm{n}^{\circ}$ 6.938, de 31 de agosto de 1981. Diário Oficial da República Federativa do Brasil, Brasília, 1981. Disponível em: <http://www.planalto.gov.br/ccivil_03/leis/L6938.htm>. Acesso em: 15 mar. 2016.

BRASIL. Ministério do Meio Ambiente. Caatinga. Disponível em: http://www.mma.gov.br/biomas/caatinga Acesso em: 27 Abr. 2018a.

CIRILO, J. A.; FERREIRA, J. P. L.; CAMPELlO NETTO, M. S. C. Aspectos gerais das regiões semi-áridas, áridas e processos de desertificação. In: CIRILO. J. A. et al. (Org). O uso sustentável dos recursos hídricos em regiões Semi-áridas. Recife: EDUFPE, 2007, p. 1931.

GADOTTI, M. Pedagogia da Terra. São Paulo: Peirópolis,. 2000.

GALVÃO, M.N.C. Possibilidades Educativas do Teatro de Bonecos nas escolas públicas de João Pessoa. 1996. Dissertação (Mestrado em Educação) - Centro de Educação, Universidade Federal da Paraíba, João Pessoa, 1996.

GIL, A. C. Métodos e Técnicas de Pesquisa Social. 6 ed. São Paulo: Atlas, 2016.

GOÉS, R. S. A música e suas possibilidades no desenvolvimento da criança e o aprimoramento do código linguístico. Revista do Centro de Educação a Distância CEAD/UDESC. 2 (1), 27-43, 2009.

IBGE. São José dos Cordeiros. Disponível em: $<$ http://www.cidades.ibge.gov.br/xtras/perfil.php?lang=\&codmun=251480\&search= paraiba|sao-jose-dos-cordeiros>. Acesso em: 02 mar. 2016.

LEAL, I.R. et al. Mudando o curso da conservação da biodiversidade na Caatinga do Nordeste do Brasil. Revista Megadiversidade, Belo Horizonte, v. 1, n. 1, 2005.

LEFF, E. Aventuras da epistemologia ambiental: da articulação das ciências ao diálogo de saberes. São Paulo: Cortez, 2012.

LIMA, I. B. Levantamento Florístico da Reserva Particular do Patrimônio Natural Fazenda Almas, São José dos Cordeiros - PB. Monografia. Universidade Federal da Paraíba - UFPB, 2004. 
LIMA, M. E. C. Feiras de ciências: o prazer de produzir e comunicar. In: PAVÃO, A.C.; FREITAS, D. Quanta ciência há no ensino de ciências. São Carlos:

EduFSCar, 2008.

MACAMBIRA, D. M. O Semi-árido nordestino: estratégias para o desenvolvimento sustentável. Rev. Princípios, v. 83, p. 33-38, 2006.

MANCUSO, R. Feira de Ciências: produção estudantil, avaliação, conseqüências.Contexto Educativo Revista Digital de Educación y Nuevas Tecnologías,

Buenos Aires, v. 6, n. 1, p. 1-5, 2000.

MEDEIROS, S. S. et al. Sinopse do Censo Demográfico para o Semiárido Brasileiro. Campina Grande: INSA, 2012.

PEREIRA, D.D. Cariris Paraibanos: do sesmarialismo aos assentamentos de reforma agrária. Raízes da desertificação? Tese (Doutorado em Recursos Naturais) - Universidade Federal de Campina Grande, Campina Grande, 2008.

PRODANOV, C.C.; FREITAS, E.C. Metodologia do Trabalho Científico: Métodos e Técnicas da Pesquisa e do Trabalho Acadêmico. Novo Hamburgo: Feevale, 2013.

RIBEIRO, M.M.G.; FERREIRA, M.S. Oficina Pedagógica: uma estratégia de ensinoaprendizagem. Natal: EDUFRN, 2001.

RICHARDSON, R.J. Pesquisa Social: Métodos e Técnicas. 3.ed. Revista eampliada. São Paulo: editora Atlas S.A, 1999.

SANTOS, C. F.; SCHISTEK, H.; OBERHOFER, M. No Semi-árido, viver é aprender. Gráfica Franciscana, 2007.

SATO, M. Educação Ambiental. São Carlos: Rima, 2002.

UNESCO. CONFITEA: Declaração de Hamburgo. Brasília: SESI/UNESCO, 1997.

VELOSO, A. L.; SAMPAIO, E. V. S. B.; PAREYN, F. G. C. Ecorregiões propostas para o bioma Caatinga. Associação Plantas do Nordeste. Instituto da Conservação Ambiental The Nature Conservancy do Brasil. Recife. 76p. 2002.

VILAR FILHO, M. D. O Sertão frugal e verdadeiro - crônica de uma convicção. Disponível em:

<http://remabrasil.org:8080/virtual/r/remaatlantico.org/sul/Members/suassuna/artigos/osertao-frugal-e-verdadeiro-2013cronica-de-uma-conviccao-artigo-de-manoel-dantas-vilarfilho/> Acesso em: 12 Abr. 2018.

ZÓBOLI, G. Práticas de Ensino: subsídios para a atividade docente. São Paulo: Ática, 2004. 